\title{
Screening Five High-toxic Organophosphorus Pesticides in Chinese tea Using Gel Permeation Chromatography-GC-MS Method
}

\author{
Xiao Zou ${ }^{a}$, Wulin $\mathrm{Li}^{b}$, Genrong $\mathrm{Li}^{\mathrm{c}}$, Xiaohui Li ${ }^{\mathrm{d}}$, Mei Long ${ }^{\mathrm{e}}$, Wuping Huang ${ }^{f}$, \\ Yan $\mathrm{Ma}^{\mathrm{g}}$, Zhaojing $\mathrm{Xiao}^{\mathrm{h}}$ \\ Chongqing Academy of Metrology and Quality Inspection, Chongqing 401123, China

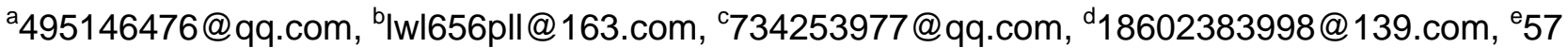 \\ 162725@qq.com, ${ }^{\mathrm{f}} 1447826865 @ q q . c o m,{ }^{\mathrm{g}} \mathrm{m} \_\mathrm{y} 0831 @ 163 . c o m,{ }^{\mathrm{h}} \mathrm{xzjxb} @ 163 . c 0 m$
}

Keywords: Gel permeation chromatography, gas chromatography-mass spectrometry, Chinese tea, high-toxic organophosphorus pesticides, multiresidue

\begin{abstract}
A gas chromatography - mass spectrometry (GC-MS) analysis method for detecting five kinds of high-toxic pesticides in Chinese tea was established. Gel permeation chromatography (GPC) was used as a sample preparation method. Purified samples were analyzed by GC-MS, detected in selected ion monitoring mode, and quantitated using the external standard method. The results showed a good linearity within the range from $0.005 \mathrm{mg} / \mathrm{L}$ to $0.500 \mathrm{mg} / \mathrm{L}$. The average recovery rates of three spiked levels were $93.86 \%$ to $106.31 \%$. All relative standard deviations (RSDs) were less than $10 \%$. The detection limit was 0.0005 to $0.0020 \mathrm{mg} / \mathrm{kg}$. This method is stable and reliable, simple to operate, and suitable for detection and analysis of trace organophosphorus pesticides in Chinese tea.
\end{abstract}

\section{Introduction}

With the widespread application of five kinds of high-toxic organophosphorus pesticides including methamidophos, methyl parathion, parathion, monocrotophos and phosphamidon in agricultural production, the problem of pesticide residues in agricultural products has received increasing attention. Since January 1, 2007, a complete prohibition of domestic sales and use of these five kinds of high-toxic organophosphorus pesticides has been implemented in China [1]. However, there are still a minority of farmers over-depending on methamidophos for its fast insecticidal effect, who continue to buy and use high-toxic pesticides such as methamidophos. To ensure the safety of Chinese tea, the detection and analysis means of five kinds of high-toxic organophosphorus pesticide residues in Chinese tea must be strengthened.

In recent years, gas chromatography - mass spectrometry (GC-MS) technique has been widely used in the detection of pesticide multi-residues. However, their high technical requirement for sample pretreatment has become the bottleneck in the application of the method. Conventional purifying method consumes a large amount of organic solvent, and its procedures are more complicated, with larger analysis error. Gel permeation chromatography (GPC) has obvious advantages with respect to the separation and purification of samples rich in fat, pigments and other macromolecules [2-4]. GPC sample separation is a physical process that can well separate macromolecules such as proteins, pigments and fat and small molecules such as pesticides, and the consumption of organic solvent for GPC is decreasing as the development of column, and it is 
simple to operate, with small analysis error. In this work, the present study used GPC techniques for sample pretreatment. Meanwhile, GC-MS was used for quantitative and qualitative analysis of five high-toxic organophosphorus pesticide residues in Chinese tea, in order to establish a GPC-GC-MS method for detection of five pesticide residues in Chinese tea.

\section{Materials and Methods}

\subsection{Instruments and reagents}

Gel permeation chromatography (GPC Ultra), Trace DSQ II GC/MS (Finnigan, USA); acetone (HPLC grade, Chengdu Kelong Chemical Reagent Factory).

Five kinds of high-toxic pesticide standards (with the concentration of $100 \mathrm{mg} / \mathrm{L}$, Agro-Environment Protection Institute of the Ministry of Agriculture) were diluted with acetone to a concentration of $0.005 \mathrm{mg} / \mathrm{L}, 0.001 \mathrm{mg} / \mathrm{L}, 0.050 \mathrm{mg} / \mathrm{L}, 0.250 \mathrm{mg} / \mathrm{L}$ and $0.500 \mathrm{mg} / \mathrm{L}$ for making the mixed standard curve.

\subsection{Instrument Parameters}

\subsubsection{Conditions for GPC}

Standard chromatographic column packing materials (biology gel 3), mobile phase: ethyl acetate: cyclohexane (1:1, V/V). The extracting solution was concentrated to $5.0 \mathrm{~mL}$ by GPC prior to sample injection for separation and purification at $5.0 \mathrm{~mL} / \mathrm{min}$. Effluent collection period was from $1300 \mathrm{~s}$ to $2000 \mathrm{~s}$. The collected fluid was concentrated to the constant volume of $5.0 \mathrm{~mL}$.

\subsubsection{Conditions for GC-MS}

Conditions for GC: Chromatographic column: TG-5MS, $30 \mathrm{~m} \times 0.25 \mathrm{~mm} \times 0.25 \mu \mathrm{m}$, helium as carrier gas, flow rate of $1 \mathrm{~mL} / \mathrm{min}$, in splitless mode, Inlet temperature: 250 ; Programmed temperature: Starting from $40^{\circ} \mathrm{C}$ and holding for $4 \mathrm{~min}$, raising to $170^{\circ} \mathrm{C}$ at $10^{\circ} \mathrm{C} / \mathrm{min}$ and holding for $5 \mathrm{~min}$, then raising to $250^{\circ} \mathrm{C}$ at $10^{\circ} \mathrm{C} / \mathrm{min}$ and holding for $8 \mathrm{~min}$.

Conditions for MS: Ion source: EI source in positive ion mode; Temperature: 250 ;C Transmission line temperature: 280 ; Chass range m/z: 20-500au; Solvent delay: 5 min.

A full scan within the range from 20 au to 500 au was first performed in a full scan mode to determine the retention time and major ions of each pesticide.The selected ion monitoring mode was then performed. The monitoring ions of five kinds of high-toxic pesticides were 94 for methamidophos, 127 for monocrotophos, 127 for phosphamidon, 109 for methyl parathion and 291 for parathion (Table 1).

Table 1 Retention time and characteristic ions of five high-toxic organic phosphorus pesticides

\begin{tabular}{cccc}
\hline Retention time/min & Pesticides & Identification ions, m/z & Quantitative ions, m/z \\
\hline 6.37 & Methamidophos & $94,95,141$ & 94 \\
9.81 & Monocrotophos & $127,192,97,109$ & 127 \\
10.39 & Phosphamidon & $127,264,138,72$ & 127 \\
10.72 & Methyl parathion & $109,125,2631$ & 109 \\
11.67 & Parathion & $291,109,97,139$ & 291 \\
\hline
\end{tabular}

\subsection{Experimental Methods}

The tea sample weighed $10 \mathrm{~g}$ was transferred into a $100 \mathrm{~mL}$ colorimetric tube, which was added with $50 \mathrm{~mL}$ of acetone and shaken well and stood for overnight. After filtration, the filtrate was collected in a $250 \mathrm{~mL}$ round-bottom flask, which was added with $25+25 \mathrm{~mL}$ of acetone for repeated extraction. After filtration, the filtrates were merged and rotarily concentrated to almost 
dryness. It was added with $15 \mathrm{~mL}$ of ethyl acetate: cyclohexane (1:1) and thoroughly dissolved and injected into GPC for purification (the sampling injection was concentrated to a constant volume of $5.0 \mathrm{~mL}$ by GPC for purification by column). The collected fluid was concentrated to a constant volume of $5.0 \mathrm{~mL}$ for GC-MS analysis.

\section{Results and Analysis}

\subsection{Regression Equation, Linear Range and Detection Limit}

A series of mixed standards of five pesticides prepared in Section 2.1 were injected for GC-MS analysis. Ion current graph was selected as Figure 1 . The linear range was from $0.005 \mathrm{mg} / \mathrm{L}$ to 0.500 $\mathrm{mg} / \mathrm{L}$ (Table 1). The sampling detection limits of five pesticides were calculated by comparing the ratio of signal to noise: $0.003 \mathrm{mg} / \mathrm{L}$ for methamidophos, $0.002 \mathrm{mg} / \mathrm{L}$ for monocrotophos, 0.001 $\mathrm{mg} / \mathrm{L}$ for phosphamidon, $0.004 \mathrm{mg} / \mathrm{L}$ for methyl parathion, and $0.003 \mathrm{mg} / \mathrm{L}$ for parathion. As the weight of sample in $10 \mathrm{~g}$, the method detection limits of five pesticides were $0.0015 \mathrm{mg} / \mathrm{kg}$ for methamidophos, $0.0010 \mathrm{mg} / \mathrm{kg}$ for monocrotophos, $0.0005 \mathrm{mg} / \mathrm{kg}$ for phosphamidon, $0.0020 \mathrm{mg} / \mathrm{kg}$ for methyl parathion, and $0.0015 \mathrm{mg} / \mathrm{kg}$ for parathion.

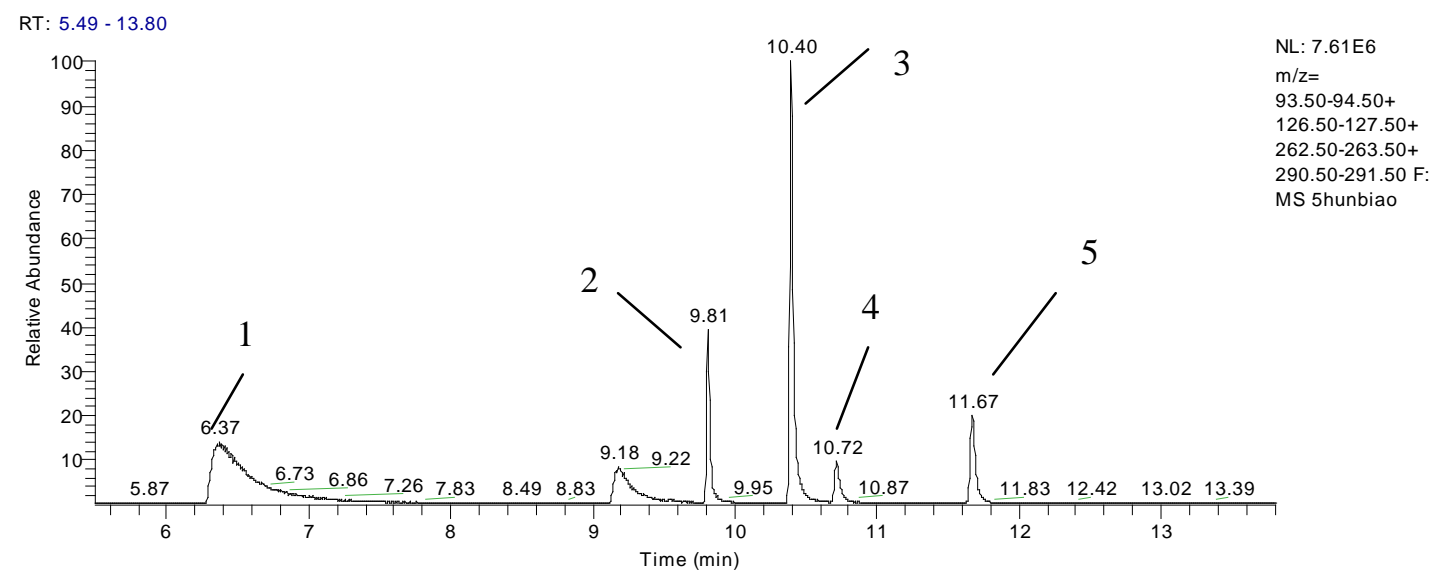

Fig. 1 SIM chromatogram of the standard samples of five organic phosphorus pesticides 1: Methamidophos; 2: Monocrotophos; 3: Phosphamidon; 4: Methyl parathion; 5: Parathion.

Table 2 Standard curve equations of the standard samples of five organic phosphorus pesticides

\begin{tabular}{ccccc}
\hline Pesticides & $\begin{array}{c}\text { Linear range } \\
/(\mathrm{mg} / \mathrm{L})\end{array}$ & Regression equation & Correlation coefficient/r & $\begin{array}{c}\mathrm{LOD} / \\
(\mathrm{mg} / \mathrm{kg})\end{array}$ \\
\hline Methamidophos & $0.005 \sim 0.500$ & $\mathrm{y}=1247678 \mathrm{x}+123$ & 0.9981 & 0.0015 \\
Monocrotophos & $0.005 \sim 0.500$ & $\mathrm{y}=486291 \mathrm{x}-54$ & 0.9989 & 0.0010 \\
Phosphamidon & $0.005 \sim 0.500$ & $\mathrm{y}=473866 \mathrm{x}-112$ & 0.9992 & 0.0005 \\
Methyl parathion & $0.005 \sim 0.500$ & $\mathrm{y}=166473 \mathrm{x}+432$ & 0.9995 & 0.0020 \\
Parathion & $0.005 \sim 0.500$ & $\mathrm{y}=312598 \mathrm{x}-11$ & 0.9996 & 0.0015 \\
\hline
\end{tabular}

\subsection{Recovery and Precision of the Method}

A certain volume of mixed standard solution was added into a blank sample, which was treated and measured according to the method described above in Section 2.3 and quantitated with the external standard method. The recovery of standard addition was repeatedly calculated for six times. The results were shown in Table 3. The average recovery rates of three spiked levels were $99.68 \%$ to $106.31 \%$, $94.14 \%$ to $98.11 \%$, and $93.86 \%$ to $98.21 \%$, respectively. RSDs were less than $10 \%$. 
Table 3 Recovery and precision of the method $(n=6)$

\begin{tabular}{cccc}
\hline Pesticides & added concentration $/(\mathrm{mg} / \mathrm{kg})$ & Recoveries $/ \%$ & $\mathrm{RSD} / \%$ \\
\hline \multirow{3}{*}{ Methamidophos } & 0.01 & 99.68 & 6.37 \\
& 0.10 & 95.67 & 9.32 \\
Monocrotophos & 0.50 & 94.74 & 8.67 \\
& 0.01 & 102.65 & 9.68 \\
Phosphamidon & 0.10 & 96.32 & 6.33 \\
& 0.50 & 94.10 & 6.98 \\
Methyl parathion & 0.01 & 100.14 & 8.66 \\
& 0.10 & 98.11 & 9.10 \\
& 0.50 & 93.86 & 7.74 \\
Parathion & 0.01 & 102.55 & 7.32 \\
& 0.10 & 96.19 & 9.78 \\
& 0.50 & 96.36 & 8.14 \\
& 0.01 & 106.31 & 8.69 \\
& 0.10 & 94.14 & 10.21 \\
& 0.50 & 98.21 & 9.68 \\
\hline
\end{tabular}

\subsection{Sample Analysis}

From the results obtained from the analysis of 20 tea samples that had been treated in accordance with the method described above in Section 2.3, it was seen that a sample from 20 tea samples was detected with phosphorus amine pesticide residues, with the concentration of $0.11 \mathrm{mg} / \mathrm{kg}$.

\section{Summary}

In the present study, a detection method for five high-toxic pesticide residues in tea samples by GC-MS after GPC pretreatment was established and used for measurement of 20 commercially available tea samples. The linear range, precision and recovery of standard addition the method were investigated. The results showed a good linearity within the range from $0.005 \mathrm{mg} / \mathrm{L}$ to 0.500 $\mathrm{mg} / \mathrm{L}$. The recovery of standard addition was between $93.86 \%$ and $106.31 \%$. The detection limit was 0.0005 to $0.0020 \mathrm{mg} / \mathrm{kg}$. It is indicated that the detection method is more suitable for detection and analysis of trace pesticide residues in Chinese tea.

\section{References}

[1]. Wu Y Q, Sun C Y. Poison control services in China[J]. Toxicology, 2004, 198(1): 279-284.

[2]. HongFei Y, Fan Z, Lian C, et al. Determination of 72 pesticide residues in olive oil by online gel permeation chromatography gas chromatography-tandem mass spectrometry[J]. Journal of Food Safety and Quality, 2016, 7(1): 166-176.

[3]. Chico J, Rúbies A, Centrich F, et al. Use of gel permeation chromatography for clean-up in the analysis of coccidiostats in eggs by liquid chromatography-tandem mass spectrometry[J]. Analytical and bioanalytical chemistry, 2013, 405(14): 4777-4786.

[4]. Xue G, CuiFen W, Ping L, et al. Determination of 11 organophosphorus pesticide multi-residues in pork by gas chromatography with gel permeation chromatography[J]. Journal of Food Safety and Quality, 2014, 5(6): 1782-1786. 